\title{
DEVELOPMENT OF A CHAMBER FOR IN SITU TOXICITY TESTS WITH SMALL FISHES
}

\author{
MELETTI, P. C. ${ }^{1}$ and ROCHA, O. ${ }^{2}$ \\ ${ }^{1}$ Universidade de São Paulo, Centro de Recursos Hídricos e Ecologia Aplicada, \\ Programa de Pós-graduação em Ciências da Engenharia Ambiental, \\ Av. Trabalhador São-carlense, 400, CEP 13566-590, São Carlos, SP, Brazil \\ ${ }^{2}$ Universidade Federal de São Carlos, Departamento de Ecologia e Biologia Evolutiva, \\ Via Washington Luís, km 235, CEP 13565-905, São Carlos, SP, Brazil \\ Correspondence to: Odete Rocha, Universidade Federal de São Carlos, Departamento de Ecologia \\ e Biologia Evolutiva, Via Washington Luís, km 235, CEP 13565-905, São Carlos, SP, Brazil, \\ e-mail: doro@ power.ufscar.br
}

(With 4 figures)

A device developed to carry out in situ experiments with small fishes is introduced in this note. In situ toxicity tests have been increasingly used with cladocerans, amphipods and fishes as an effective tool in monitoring environmental quality. Furthermore, exposing test organisms in situ may reduce the uncertainties of extrapolation from the laboratory (Hoffman et al., 1995). During acute toxicity tests, organisms are maintained in test chambers immersed in the body of water under evaluation for a period of 96 hours. Besides the simplicity of operation, in this kind of experiment the organisms are exposed to the toxic agents under real conditions (Boudou \& Ribeyre, 1989; Burton, 1992). Several workers have already attested to the efficiency and practicality of such devices. According to Burton (1991), this technique is relatively simple and eliminates possible errors induced by the sampling and manipulation of sediments in the laboratory. Furthermore it takes into account important conditions in the evaluation of sediment toxicity, such as insolation, diurnal variations of temperature, dissolved oxygen, turbidity, water current, sediment integrity and interactions with local microfauna.

Pereira et al. (1999), carried out in situ tests with zooplankton species (Daphnia magna and Ceriodaphnia dubia) in a reservoir contaminated by metals from abandoned mines and concluded that this kind of experiment constitutes a rapid and efficient way of evaluating environmental contamination and validating laboratory experiments. The chamber used for microcrustaceans was developed by those authors and inspired the shape of the chamber developed for the present study, de- signed to replace an earlier model, which suffered from some limitation. According to the description of Pereira et al. (1999), their chambers had a volume of $50 \mathrm{ml}$, were made of polypropylene and had three windows or apertures (two lateral and one at the bottom, which made contact with the sediment) of diameter $20 \mathrm{~mm}$ each, covered by a net of $50 \mu \mathrm{m}$ mesh size.

The chamber introduced here (Figs. 1, 2 and 3 ) is built from PVC tubes of diameter $150 \mathrm{~mm}$, the appropriate caps for the tubes, which are commercially available, nylon nets of $2 \mathrm{~mm}$ mesh, rivets and screws of stainless steel and nylon string of diameter $3.5 \mathrm{~mm}$. There are 5 windows, 4 lateral and 1 at the bottom, for contact with sediment. In order to confer stability during immersion in places with a strong current and also to anchor the apparatus in the sediment the chamber has an iron base $2.25 \mathrm{~kg}$. This square base has $250 \mathrm{~mm}$ sides and was built out with iron rods of diameter 19 $\mathrm{mm}$, a foot at each corner and L-shaped supports to attach it to the chamber. The chamber body has height $200 \mathrm{~mm}$, diameter of $150 \mathrm{~mm}$ (internal diameter $145 \mathrm{~mm}$ ); volume $3,300 \mathrm{ml}$; lateral windows with diameter $55 \mathrm{~mm}$ each; bottom window with $145 \mathrm{~mm}$; cap as to allow introduction and inspection of fishes, of $151 \mathrm{~mm}$ internal diameter, a tight fitting and without thread, but having a stainless steel screw in the edge as a security device against disassembling. The cap has 9 holes of $2.5 \mathrm{~mm}$ each, for air to escape during immersion. A nylon string is attached at the top of the chamber, used to submerge or immerse it and attach it to an outside structure. The body of the chamber is attached to the anchor/base by 4 stainless steel rivets $(4.0 \mathrm{~mm})$. 


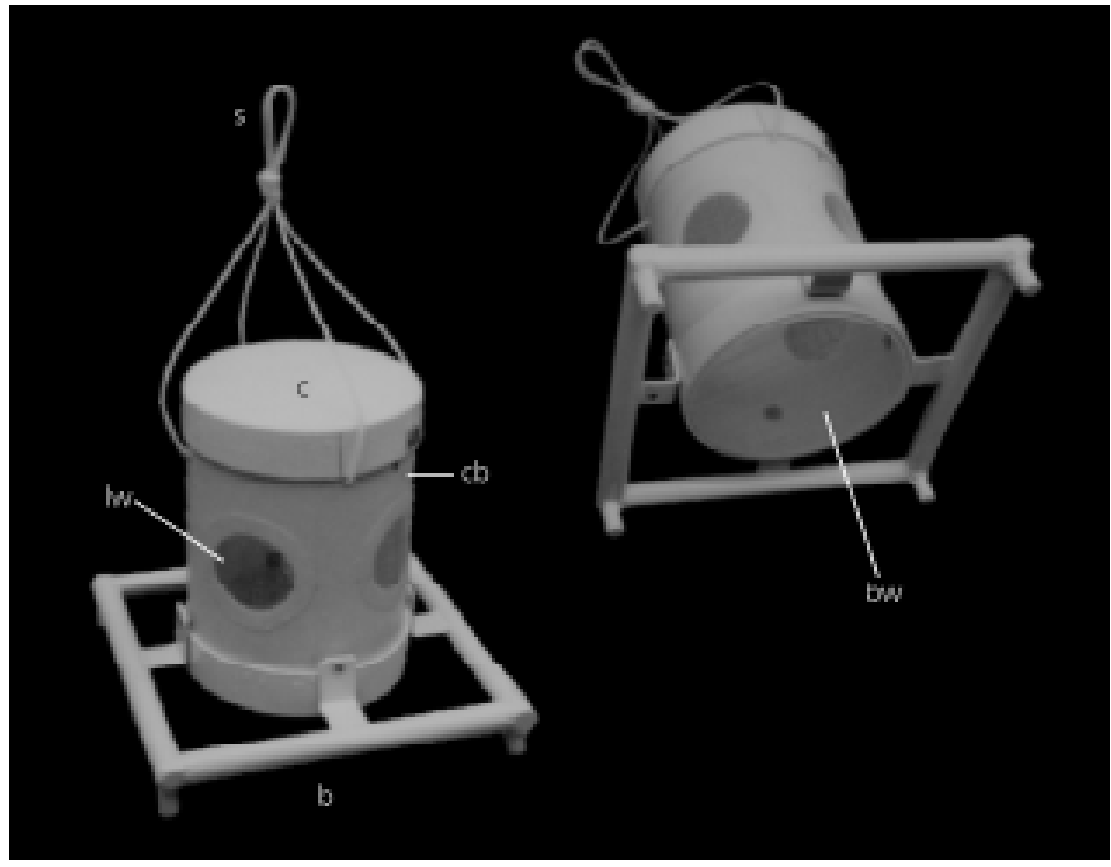

Fig. 1 - Side and bottom view of the chamber: cb - chamber body; b - iron base; $\mathrm{c}$ - cap; lw - lateral window; bw - bottom window; and $\mathrm{s}-$ string.

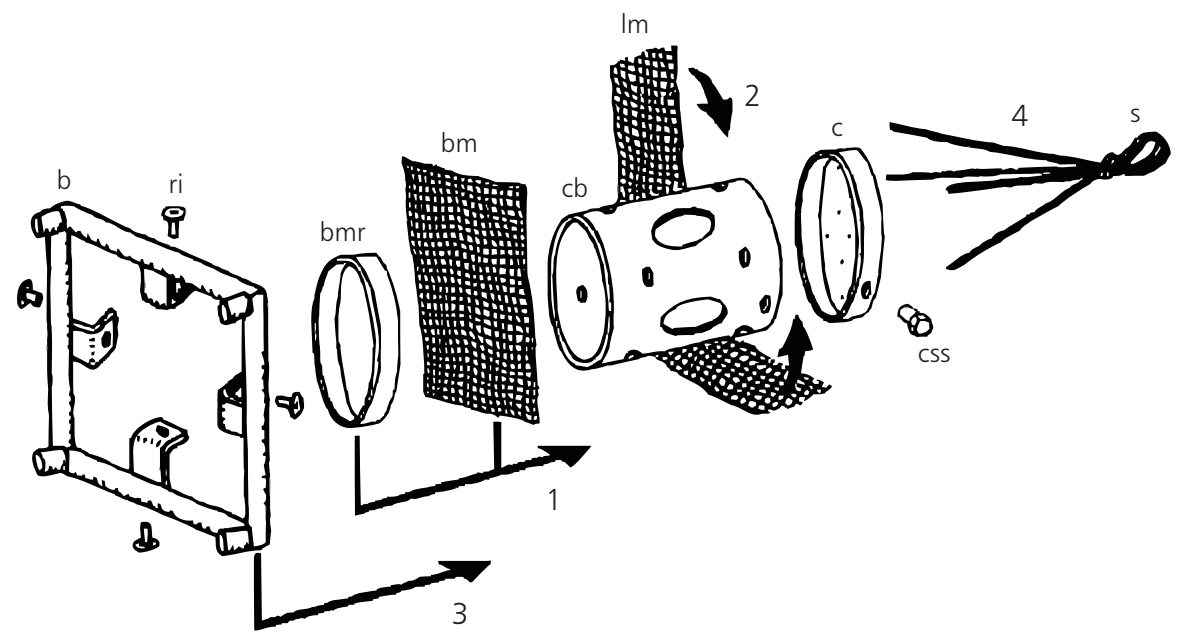

Fig. 2 - Sketch of the main parts of the chamber: b - iron base; ri - rivets; bmr - bottom mesh ring; bm - bottom mesh; $\mathrm{cb}$ - chamber body; $1 \mathrm{~m}$ - lateral mesh; c - cap; css - cap safety screw; and s - string. Order of assembly: (1) Fit bm to cb with the PVC ring; (2) seal $1 \mathrm{~m}$ over the 4 lateral $55 \mathrm{~mm}$ apertures; (3) join b to cb by rivets; and (4) tie s around cb. 


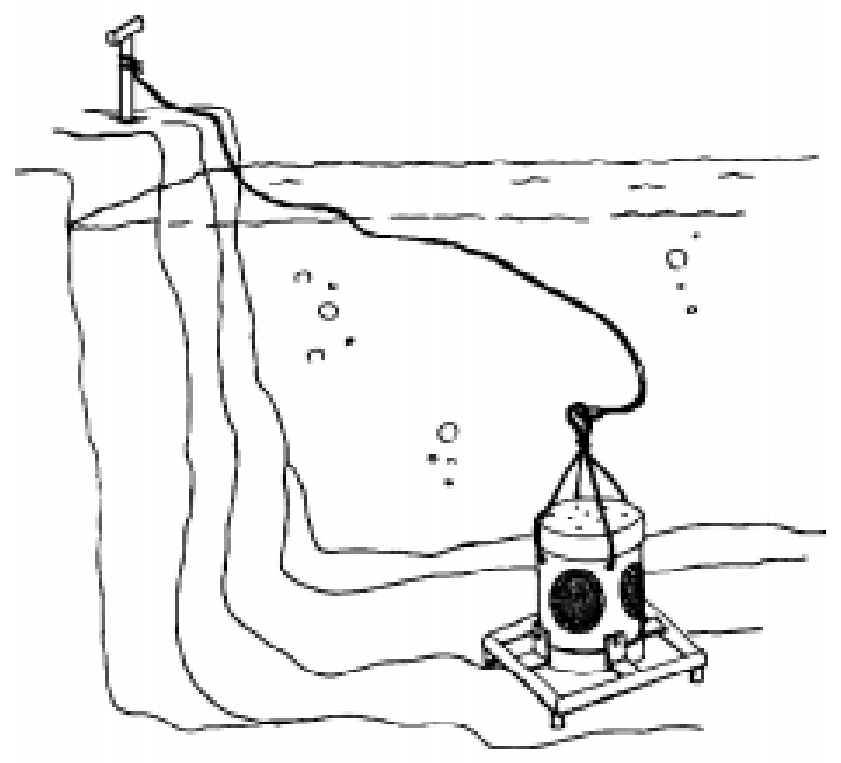

Fig. 3 - Sketch showing the positioning of the chamber in a river.

A glue was used to stick the meshes to the lateral windows. At the bottom window, which is larger, a ring is used to hold the mesh by pressure, without glue. The ring was cut from the cap which was originally $75 \mathrm{~mm}$ in height, so that after cutting, both, the ring and a shorter cap of $35 \mathrm{~mm}$ height were obtained. At the lateral windows, the mesh was glued with a synthetic non-silicon and nonacetic resin as follows: a mesh band of $85 \mathrm{~mm}$ width was provisionally attached to the tube by elastic rings. Glue was applied at the border of the window in the outside of the chamber. After 24 hours the excess mesh was trimmed with a cutter, in a circular shape around the windows. Fig. 2 shows details of the chamber assembly. After drying the glue the chambers were maintained submersed in distilled water for 48 hours, in order to test it. The iron base was painted with powder electrostatic painting, epoxy type, non-toxic.

The chambers described here were used to carry out acute toxicity tests $(96 \mathrm{~h})$ in several locations in Piracicaba and Mogi-Guaçu river basins (São Paulo State) and also in the Tibagi river (Paraná State), Brazil. A native species of fish,
Serrapinnus notomelas (Characidae, Characiformes) was utilized as test organism. Ten adult specimens (meanweight $=0.30 \mathrm{~g}$ ) were placed in each chamber. Daily observations were made and it was found that the chambers were not displaced by the flow of the river and that there was no aggressive behaviour among fish during the experiments, apparently indicating that conditions were adequate in the chamber. Also it was observed that there is direct contact with the sediment, without, however, great amounts of sediment entering the chamber. In some localities it was possible to observe annelids, platyhelminthes and chironomid larvae inside the chamber, indicating that fish would be able to feed on bottom organisms. The size of the mesh would also allow the entrance of algae and microinvertebrates such as rotifers and micro-crustaceans, which would be an advantage when mixing fishes of differing feeding habits. The analysis of fish stomach contents could be to confirm the hypothesis, although feeding is not acrucial factor in the period of 96 hours, for a number of fish species. No mortality was observed in a total of 200 fishes used in the tests, suggesting that the chamber design 
is adequate, with space enough not to stress them, and that the material of which the chamber was made is non- toxic.

For very sensitive organisms the materials must be tested before the chamber is constructed. Pereira et al. (1999), for example, concluded that white thermal glue was less toxic to the microcrustaceans than the silicone and yellow thermal glues. In the case of the chamber here described, common aquarium materials were used and the immersion period to which the chamber was submitted before use is probably important to remove residues. Also, the fact that during the in situ test there is a continuous flow of water does minimize these problems. The success of the test depends on several factors, among them the manipulation of the chamber while inspecting, counting or taking out test-organisms. For the inspection, it is recommended that the chamber is placed in a tray filled with water taken from the place experiments are being performed (Fig. 4).

Despite being originally designed for use in toxicity tests with fish, this device can be used for other aquatic organisms and also for different purposes, whenever the organism needs to be exposed to real in situ conditions, where necessary changing mesh sizes, building smaller versions or using nylon bags that can be placed inside the chamber.

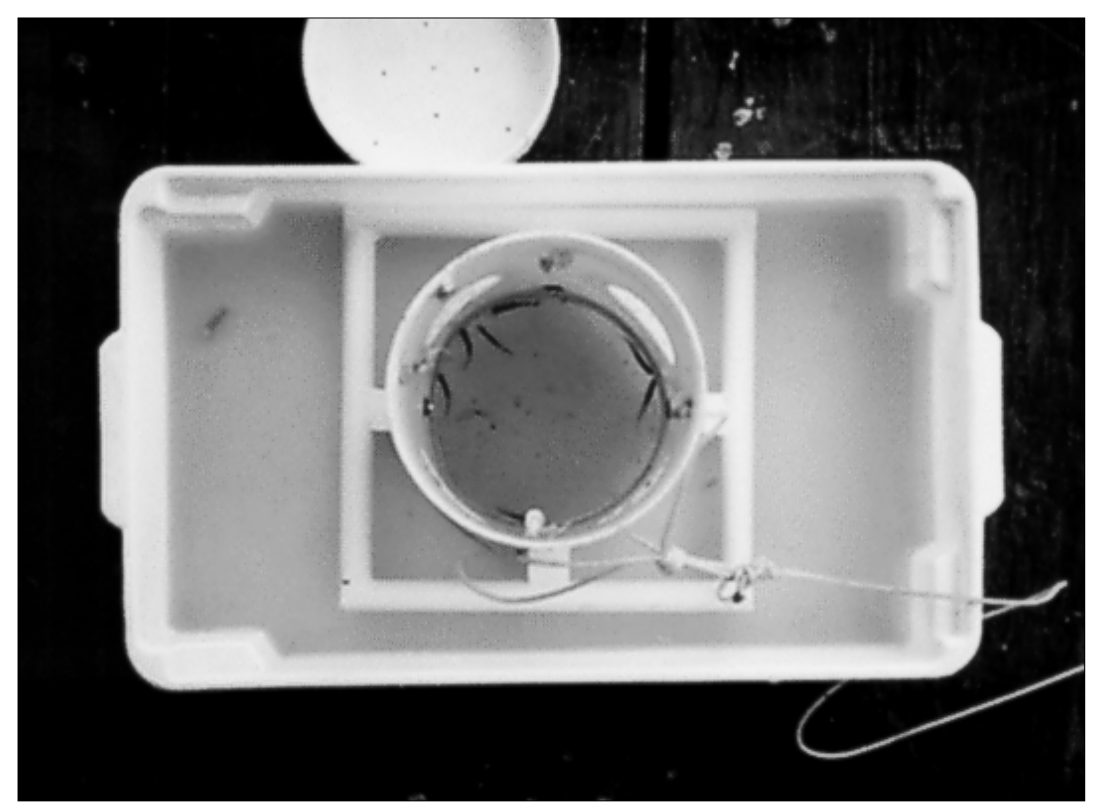

Fig. 4 - Upper view of an open chamber placed in the inspection tray to observe the fishes.

Acknowledgments - The authors thank Fapesp and the Pronex program (Finep - CNPq) for the financial support.

\section{REFERENCES}

BOUDOU, A. \& RIBEYRE, F., 1989, Aquatic ecotoxicology: fundamental concepts and methodologies. Vol. II. CRC Press, Boca Raton, 320p.

BURTON Jr., G. A., 1991, Assessing the toxicity of freshwater sediments. Environ. Toxicol. Chem., 10: 1585-1627.
BURTON Jr., G. A., 1992, Sediment toxicity assessment. Lewis Publishers, Boca Raton, 457p.

HOFFMAN, D. J., RATTNER, B. A., BURTON Jr., G. A. \& CAIRNS Jr., J., 1995, Handbook of ecotoxicology. Lewis Publishers, Boca Raton, 755p.

PEREIRA, A. M. M., SOARES, A. M. V. M., GONÇALVES, F. \& RIBEIRO, R., 1999, Test chambers and test procedures for in situ toxicity testing with zooplankton. Environ. Toxicol. Chem., 18: 1956-1964. 